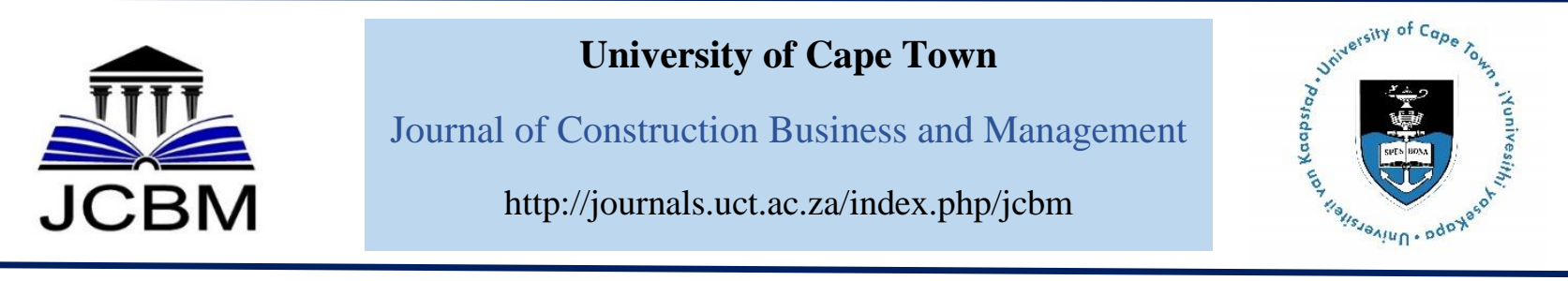

\title{
Environmental and Socio-Economic Impacts of Ojodu-Berger Road Upgrade, Lagos, Nigeria
}

\author{
W.A. Alade ${ }^{1}$ \\ ${ }^{1}$ Department of Urban and Regional Planning, University of Lagos, Lagos, Nigeria
}

Received 14 june 2019; received in revised form 1 October 2019 and 12 December 2019; accepted 20 December 2019. https://doi.org/10.15641/jcbm.4.1.785

\begin{abstract}
Extensive road project in large cities produces diverse impacts. This study attempts an assessment of the environmental and socio-economic effects of a recent road upgrade, the mitigating measures of adverse effects experienced and their effectiveness in Ojodu Berger community, a major transport node in Lagos, southwestern Nigeria. Using a survey research design through questionnaire administration, 120 respondents comprising of 50 residents, 40 traders and 30 transport operators were sampled using the purposive sampling technique. The Relative Significance Index (RSI) of project impacts was measured using 27 variables as identified in the literature and general observation of situations in the project environment before the survey. On a 5-point Likert scale at the pre-construction, construction and post-construction phase of the project. The study reveals poor environmental conditions at the pre-construction phase, which became escalated in the construction phase; noise pollution is the most significant impact (RSI =4.36). At the post-construction phase, encroachment on pedestrian facilities is the most significant impact $(\mathrm{RSI}=4.20)$. Socio-economic impacts such as increased rental value, unemployment and displacement of businesses were also significant. The Mean Index (MI) of 3.14 for the construction phase impacts was the highest compared to 3.00 at the pre-construction phase and 3.02 at the post-construction phase. Mitigating measures against adverse impacts were both effective and ineffective, while some adverse impacts were not mitigated. There was no clear evidence that an impact study was done before project implementation. The study recommended strong government commitment to environmental and social impacts assessment of road development, more robust stakeholders' engagement for the formulation of strategies and measures to address the adverse impacts of similar projects in the future.
\end{abstract}

Keywords: Construction, Environmental, Impacts, Social, Upgrade.

\section{Introduction}

The expansion and provision of road infrastructure around the world have been unprecedented in the last two decades (Alamgir et al., 2018). Since 2000, the length of official roads has increased by 12 million kilometres worldwide, and it is expected that there will be a further increase of about 25 million kilometres to be built by the year 2050 (Dulac, 2013). This massive expansion in road infrastructure provision can be attributed to governments' set vision to make public, economic and social services physically more accessible to all the people in the rural and urban areas around the world (ERA, 2012; Arethun and Bhatta, 2012). Provision of access routes has higher potentials for far-reaching implications on the bio-physiochemical and socio-economic environment of the host community as well as the living conditions of dwellers (Soneye, 2007).

Around $90 \%$ of all new infrastructure projects are occurring or expected to occur in developing nations of the world (Dulac, 2013). In Africa, the 35 major 'development corridors' being planned or currently in progress would crisscross the continent, collectively exceeding 53,000 km in length (Laurance et al., 2015). Roads that are effectively located and constructed can provide positive outcomes for economic growth and social integration, and access to larger urban markets for local producers (Bryceson et al., 2008). On the contrary, roads that are poorly planned or executed can create numerous environmental (Lawrence et al., 2015), economic (Collier et al., 2015), and socio-political problems (Bambach and Mitchell, 2015). For example, a

\footnotetext{
${ }^{1}$ Corresponding Author.

Email address: aalade@unilag.edu.ng
} 
proposed 'superhighway' in Nigeria would have cut through much of the remaining habitat, allowing the government to seize extensive traditional communityowned lands while providing questionable economic benefits (Mahmoud et al., 2017).

In the last four decades, there has been a global concern for sustainable development with environmental protection as one of its primary focus. This is to ensure that adverse impacts arising from physical developments such as road construction in cities are adequately managed. In Nigeria, there have been remarkable improvements in the development of road infrastructure since the national oil boom of the early 1970s (Soneye, 2010). The impacts of these road projects are not only permanent but irreversible (Ojo, 1988). However, these impacts are hardly monitored for necessary action due to limited planning consideration and institutional gridlocks amongst regulatory agencies in the decision-making process (Soneye, 2010) coupled with a dearth of required records and analytical tools for operations. This trend is against global practices of sustainable development.

This study explores the environmental and socioeconomic impacts of road upgrade in Ojodu Berger, a nodal community in Lagos, Nigeria based on local perception to provide information on the effects of these projects before, during and after implementation and using the outcome to influence the direction of similar projects in the future. Preliminary studies revealed that the project lacked an environmental impact study, hence, the impacts before, during and after construction and the mitigating measures and their effectiveness were investigated.

\section{The Study Area}

Lagos is the most populous city in Nigeria and third in Africa after Cairo and Kinshasa. The population is currently estimated at 23 million people which is approximately $11.5 \%$ of the country's population. The vehicle population of Lagos is about 3 million and about $93 \%$ of passenger and goods movement is by road. Over $95 \%$ of the public transport system is controlled by the informal sector (LASG, 2019). Ojodu-Berger, the study area is a nodal community and situated along LagosIbadan expressway at the northern boundary of the metropolis and Lagos state. This location makes the community a significant transport and commercial node mixed with residential areas. It is the first drop-off point for people coming into Lagos from other parts of the country. This situation puts much pressure on the community in the form of heavy vehicular and pedestrian traffic leading to congestion on the Lagos-Ibadan expressway and vehicular/pedestrian conflicts in the commercial and terminal areas. Besides, many cases of road traffic accidents are recorded in the community.

The haphazard land use structure, weak planning control of commercial and road terminal activities, and the absence of pedestrian facilities for commuters transferring from one side of the Lagos-Ibadan expressway to the other compound the chaotic situation and therefore necessitates the upgrade of roads and intersections connecting to the expressway for good traffic flow. The construction of road terminals and an extensive pedestrian bridge were also done to inject sanity for proper management of traffic in the neighbourhood. Based on preliminary findings, there was no evidence of a detailed environmental impact study on the project. Besides, the researcher observed at the construction phase of the projects that mitigation efforts adopted by the contractor to address some of the visible adverse impacts were inadequate and uncoordinated. This situation provides the basis for this study.

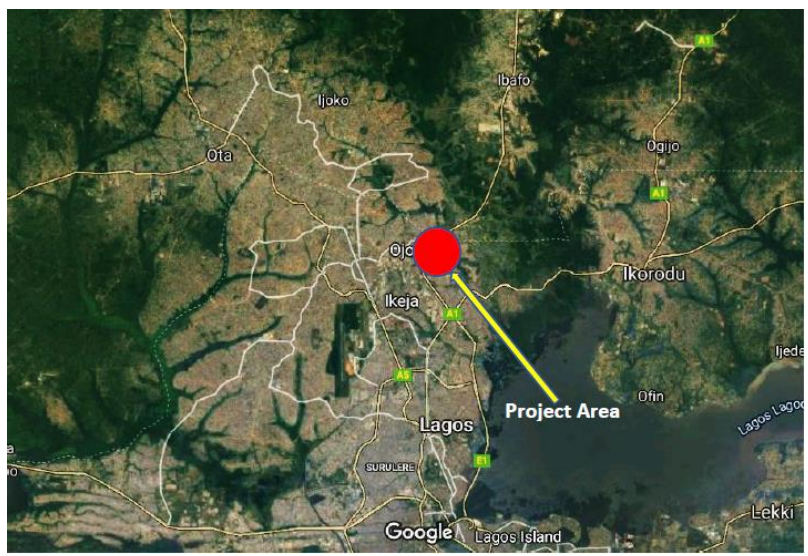

Source: Google map (2017)

Figure1: Location of Project Area within Lagos Megacity

\section{Literature Review}

\subsection{Environmental Impacts of Road Projects}

The construction of roads can affect biodiversity both directly, as an immediate consequence; or indirectly, as a result of human activities that are facilitated by new roads (Trombulak and Frissell, 2000; Laurance et al., 2009). These direct effects can be in the form of vehicle and wildlife collisions (Clevenger et al., 2003), reduced reproductive capacity of sensitive species as a result of chronic road noise (Kociolek et al., 2011) and behavioural avoidance of roads by endangered animal species (Whitworth et al., 2015). Besides, roads can also function as barriers limiting the movements of animals between various habitats and territories.

Road infrastructure can also produce impacts that are beneficial to the sustainable development of countries and cities. The benefits from efficient road transport are felt at all levels of the society, directly or indirectly, such as to include improved national economy, social income, wealth and job creation, health care, public transport and general service delivery. Improvement of all these areas is desirable for the current national aspirations, including inter-sectoral growth collaborations (Perkins, 2011). The attainment of the Sustainable Development Goals by 2030 is heavily reliant on the provision of infrastructure, efficient road network being the key unit.

Development of new roads and improvement of existing facilities have potentially adverse effects on the physical environment and social well-being of the communities as well as natural habitats. Among the potential negative impacts from road construction projects could include: environmental pollution from construction activities, the risk to health and safety of the residents and employees, increased surface runoff, socio-cultural changes including demolition of structures, displacement 
of human settlement/commercial centres, increased traffic, increased ambient air pollution, increased potential for road accidents, flooding and associated disasters among other impacts. Other anticipated impacts from road projects are the destruction of land, vegetation, change in land use pattern (Wegener, 2004), and possible interference with natural eco-balance.

\subsection{Socio-economic Effects of Road Projects}

The proponents of road projects frequently portray their proposed projects as a panacea for many social aspirations (Laurance et al., 2014). In most cases, however, the broad societal risks that new roads can create are rarely identified or weighted adequately (Laurance et al., 2015). The construction of roads in remote areas, for example, can lead to increases in illicit logging, mining, poaching, smuggling and drug production (McSweeney et al., 2014). Such practices can exacerbate environmental and social problems, defraud governments of tax and royalty revenues, and require increased expenditures for monitoring and law enforcement (Asner et al., 2013).

During the initial phases of development, real or perceived inadequacies in community consultation or forced land reclamations can be flash-points for conflict. Community dissatisfaction may be aroused if benefits from roads are distributed inequitably, such as the inadequate provision of employment opportunities for residents or perceived government corruption. Road projects in frontier areas commonly lead to an influx of migrant workers or colonists, with potentially adverse impacts on local inhabitants (Suarez et al., 2009). Among the undesirable effects are increased demands for 'immoral' services such as prostitution and black-market products (Clements et al., 2014), an increase in sexually transmitted infections (Carswell, 1987) and an erosion of traditional social structures (Rudel, 2005). Such challenges can provoke community conflict, potentially delaying road development or increasing its economic costs. Some frontier communities living in the aftermath of new roads are highly polarized between 'locals' and 'migrants' (Colombijn, 2002). Social risks do not end once a road project has been completed. For instance, vehicle crashes have substantial socio-economic impacts, averaging $3.3 \%$ of total GDP in high-income countries and at least 1.1 to $2.9 \%$ of total GDP in lower-income countries (Wijnen and Stipdonk, 2016).

New roads act as invasion corridors, facilitating incursions of human and animal pathogens and disease vectors (Laurance et al., 2009). People living near roads in India, Brazil, and Uganda have reported increased incidences of dengue fever, malaria and HIV, respectively (Carswell, 1987). Exotic plants and animals, including many species deleterious to humans or agriculture, often use road verges to invade new lands. Little fire ants (Wasmannia auropunctata), for example, invade 60 times faster along logging roads in African rainforests than in undisturbed forests; the intense stings from this species repel and even kill livestock, wildlife and people (Walsh et al., 2004).

For indigenous groups in remote areas, new roads can have irrevocable effects (Colombijn, 2002). Roads have decimated some indigenous populations via introduced diseases and forced or voluntary migration (Koji and
Hoban, 1997). In the 1970s, the construction of the TransAmazon Highway led to the deaths of $45 \%$ of one indigenous group in a single year (Hecht and Cockburn, 2010). Roads penetrating tribal territories can lead to an influx of non-indigenous squatters and land speculators seeking to appropriate land titles. Additional impacts such as alcohol abuse, prostitution, illegal mining and social domination by colonists can arise (Singleton et al., 2004). Roads penetrating remote areas are often perceived as drivers of increased aggression, lawlessness and other 'frontier society' behaviour (McSweeney et al., 2014).

Transportation projects can take many forms (OECD, 2002). According to Banister and Berechman (2000), transportation developments that have taken place since the beginning of the industrial revolution have been linked to growing economic opportunities. At each stage of human societal development, a particular transport mode has been developed or adapted. However, it has been observed that throughout history that no single transport has been solely responsible for economic growth. Instead, modes have been linked with the direction and the geographical setting in which growth was taking place. For instance, major flows of international migration that occurred since the 18th century were linked with the expansion of international and continental transport systems (Wanjiku, 2014). Roads are a critical enabling condition for improving living conditions in rural areas. However, the distribution of socio-economic benefits resulting from a rural road is a separate issue, and there are no guarantees or inherent mechanisms to ensure that these benefits will be distributed equitably between the poor and the non-poor in communities (Asian Development Bank, 2006).

Road construction activities themselves have been found to generate significant economic growth. According to the European Investment Bank's (EIB) 2002 study "Contribution of Major Road and Rail Infrastructure Projects to European Development", out of $14 \mathrm{road}$ infrastructure construction projects, ten had a Return on Investment (ROI) of at least $13 \%$, and only one resulted in a net loss. Socio-economic impact assessment focuses on evaluating the impacts the development has on community social and economic well-being (Edwards, 2000). This analysis relies on both quantitative and qualitative measures of impacts. Development impacts are generally evaluated in terms of changes in community demographics, housing, employment and income, and aesthetic qualities of the community.

\section{Research Methodology}

This study compares the environmental and socioeconomic indices of the study area before, during and after construction towards road upgrade to establish the degree of project impacts. The study relied on local perception and used mixed methods (quantitative and qualitative) to source data from residents, traders and transport operators in the study area with the aid of structured questionnaire, interviews and focus group discussions with representatives of transport unions and personal observations. This method was used by Budiyati and Wahyu (2014) for the study of social and economic impacts of national road improvement in Kabupaten 
Dompu, Nusa, Tenggara Barat, Indonesia. The primary data obtained from respondents include the socioeconomic characteristics of the people, the environmental and socio-economic situation before the project and the impacts arising from the construction of roads, terminals and the pedestrian bridge and the mitigating measures adopted to limit adverse impacts. Google map was used to establish the boundary and coverage of the project area.

Convenient sampling technique was adopted in determining the sample size for this study as surveys and questionnaire administration were carried out based on the availability and readiness of respondents for interview. Besides, this technique was used due to the unplanned nature of the area and a dearth of information highlighting the number of people per respondent category. For ease of sampling, the study area was divided into three zones: residential, commercial and road terminals to obtain information from residents, traders and transport operators, respectively. A convenient selection of 120 respondents from the three zones was adopted, and this includes 50 residents, 40 traders and 30 transport operators. The study was limited to a radius of $0.5 \mathrm{Km}$ from the location of the road upgrade.

Table 1: Sample size distribution

\begin{tabular}{lcc}
\hline Zone & No of respondents & $\%$ \\
\hline Residential & 50 & $44.5 \%$ \\
Commercial & 40 & $33.3 \%$ \\
Road terminals & 30 & $22.2 \%$ \\
Total & 120 & $100.0 \%$ \\
\hline
\end{tabular}

Source: Author's study

Based on respondents' perception, 27 environmental and socio-economic variables as identified in the literature (Lagos Metropolitan Area Transport Authority, 2012; Morgan, 2012; Ijigah, Jimoh, Aruleba \& Ade, 2013) were measured on a 5-point Likert scale to establish the Relative Significance Index (RSI) of the road project impacts at the pre-construction, construction and postconstruction. The 5-point scale of $1-5$ is presented as follow: $(1=$ very low, $2=$ low, $3=$ moderate, $4=$ high, 5 $=$ very high). An impact is considered significant when the associated RSI is higher than the Mean Index (MI) and vice-versa. The RSI is calculated as:

$R S I=\frac{\text { Significance Weight Value }(S W V)}{\text { Total number of responses }(n)}$

Where: $S W V=1 r 1+2 r 2+3 r 3+4 r 4+5 r 5$

$r=$ Ratings of respondents

$S W V=\sum_{i=1}^{5} X i Y i$

Where: $X=$ number of respondents, $Y=$ weight assigned to an impact by respondents
Mean Index $(M I)=\frac{\sum R S I}{N a}$

Mean Deviation $(M D)=M I-R S I$

Where: $n=$ Total number of responses (sample size)

$r=$ Ratings of respondents

$\mathrm{Na}=$ Count of identified impacts

Based on respondents' perception, the effectiveness of mitigating measures against adverse impacts of the project was classified as 'effective' or 'ineffective'. Effectiveness of mitigating measures was based on the percentage of respondents. A mitigating measure is considered effective when not less than $50 \%$ of respondents rated or considered it as such.

\section{Findings and Discussion}

The section contains the analysis of the environmental and socio-economic situations of the project area at the preconstruction, construction and post-construction phase and the effectiveness of mitigating strategies against adverse impacts of the road project based on local perception.

\subsection{Pre-construction Phase (Baseline) Situation}

The pre-construction phase represents the baseline for the study. The analysis presented in Table 2 represents the prevailing environmental and socio-economic situation of the project area at the pre-construction phase. The Mean Index (MI) established from the 27 variables is 3.00 and 12 (eight environmental and four socio-economic) of these variables were significant as they have RSI higher than 3.0. In order of significance, the twelve variables include children access to school (3.84), traffic congestion (3.77), noise pollution (3.76), access to health facilities (3.65), access to shopping (3.63), poor road terminal (3.55), hindered access to the neighbouring community (3.51), air pollution (3.49), poor road condition (3.45), access to recreation facilities (3.21), vehicular/pedestrian conflict (3.03) and poor sanitation (3.01).

The results suggest that before the road project, the neighbourhood had always experienced adverse environmental conditions such as high levels of traffic congestion, noise pollution, poor road terminal, air pollution, poor condition of roads, vehicular/pedestrian conflict and poor sanitation. The unplanned land use, poorly organised terminals and poor traffic management may be responsible for the observed situation before the road project, which was aimed to ameliorate the adverse conditions in the project area. The results of the baseline studies on the environmental and socio-economic situation at the pre-construction of the road project reveal that environmental situations were generally poor. 
Table 2: Pre-construction (baseline) environmental and socio-economic indices

\begin{tabular}{|c|c|c|c|c|c|c|c|c|c|}
\hline \multirow[t]{2}{*}{ Environmental indicators } & \multicolumn{5}{|c|}{$\begin{array}{l}\text { Impacts' significance ratings } \\
\qquad(\mathrm{n}=\mathbf{1 2 0})\end{array}$} & \multirow[t]{2}{*}{ SWV } & \multirow[t]{2}{*}{ RSI } & \multirow[t]{2}{*}{ MI } & \multirow[t]{2}{*}{ MD } \\
\hline & 1 & 2 & 3 & 4 & 5 & & & & \\
\hline Noise pollution & 5 & 13 & 9 & 72 & 21 & 451 & 3.76 & & 0.76 \\
\hline Water pollution & 11 & 50 & 45 & 11 & 3 & 272 & 2.27 & & -0.73 \\
\hline Air pollution & 8 & 16 & 28 & 45 & 23 & 419 & 3.49 & & 0.49 \\
\hline Flooding & 4 & 45 & 59 & 12 & - & 319 & 2.66 & & -0.34 \\
\hline Traffic congestion & 10 & 5 & 16 & 61 & 28 & 452 & 3.77 & & 0.77 \\
\hline Poor road condition & 14 & 1 & 45 & 37 & 23 & 414 & 3.45 & & 0.45 \\
\hline Poor road terminals & 1 & 41 & 6 & 35 & 37 & 426 & 3.55 & & 0.55 \\
\hline Encroachment on pedestrian facilities & 44 & 13 & 7 & 39 & 17 & 332 & 2.77 & 3.00 & -0.23 \\
\hline Frequent road accident & 18 & 44 & 27 & 18 & 13 & 324 & 2.70 & & -0.30 \\
\hline Vehicular/Pedestrian conflict & 19 & 11 & 55 & 18 & 17 & 363 & 3.03 & & 0.03 \\
\hline Frequent change in land use & 24 & 49 & 25 & 3 & 19 & 304 & 2.53 & & -0.47 \\
\hline Impaired urban aesthetics & 35 & 43 & 6 & 14 & 22 & 305 & 2.54 & & -0.46 \\
\hline Poor sanitation & 8 & 47 & 23 & 20 & 22 & 361 & 3.01 & & 0.01 \\
\hline Hindered access to adjoining neighbourhoods & 8 & 10 & 35 & 47 & 20 & 421 & 3.51 & & 0.51 \\
\hline Impaired mobility & 19 & 13 & 27 & 49 & 12 & 382 & 3.18 & & 0.18 \\
\hline \multicolumn{10}{|l|}{ Socio-economic indices } \\
\hline Crime/Insecurity & 13 & 43 & 35 & 19 & 10 & 330 & 2.75 & \multirow{13}{*}{3.00} & -0.25 \\
\hline Housing shortage & 24 & 47 & 34 & 15 & - & & 2.33 & & -0.67 \\
\hline Rental value & 17 & 15 & 62 & 21 & 5 & 342 & 2.85 & & -0.15 \\
\hline Displacement of businesses & 8 & 63 & 30 & 7 & 12 & 312 & 2.60 & & -0.40 \\
\hline Unstable Income source & 40 & 29 & 29 & 15 & 7 & 280 & 2.33 & & -0.67 \\
\hline Unemployment & 17 & 20 & 50 & 15 & 18 & 357 & 2.98 & & -0.02 \\
\hline Access to shopping & 13 & 1 & 28 & 53 & 25 & 436 & 3.63 & & 0.63 \\
\hline Access to health & 6 & 10 & 25 & 58 & 21 & 438 & 3.65 & & 0.65 \\
\hline Children's access to education & 5 & 3 & 25 & 60 & 27 & 461 & 3.84 & & 0.84 \\
\hline Access to recreation facilities & 21 & 10 & 27 & 47 & 15 & 385 & 3.21 & & 0.21 \\
\hline Disruption of power supply & 21 & 53 & 33 & 8 & 5 & 283 & 2.36 & & -0.64 \\
\hline Disruption of water supply & 16 & 68 & 31 & 5 & - & 265 & 2.21 & & -0.79 \\
\hline Total & & & & & & & 80.96 & & \\
\hline
\end{tabular}

Source: Authors field survey, 2017

The results suggest that before the road project, the neighbourhood had always experienced adverse environmental conditions such as high levels of traffic congestion, noise pollution, poor road terminal, air pollution, poor condition of roads, vehicular/pedestrian conflict and poor sanitation. The unplanned land use, poorly organised terminals and poor traffic management may be responsible for the observed situation before the road project, which was aimed to ameliorate the adverse conditions in the project area. The results of the baseline studies on the environmental and socio-economic situation at the pre-construction of the road project reveal that environmental situations were generally poor.

\subsection{Construction Phase Impacts}

Table 3 captures the outcome of the analysis of environmental and socio-economic indices of the project area at the construction phase with a Mean Index of 3.14 which is relatively higher than the 3.00 obtained at the pre-construction phase. The table reveals that 15 (ten environmental and five socio-economic) of these variables have RSI higher than 3.0. and 13 of them have RSI higher than 3.14 (the Mean Index). In order of significance, the thirteen variables with RSI higher than the MI include noise pollution (4.36), traffic congestion (4.03), poor road condition (3.83), displacement of business (3.70), unemployment (3.69), change in land use (3.48), higher rental value (3.45), vehicular/pedestrian conflict (3.43), poor road terminal (3.41), unstable income (3.25), impaired urban aesthetics (3.24), air pollution (3.20) and water pollution (3.18).

Table 3 further revealed that the scale and mix of environmental and socio-economic indices observed at the construction phase are somehow different from the pre-construction phase results. For example, the RSI of 4.36 for noise pollution is far higher than the preconstruction phase, suggesting that the road project worsen the noise pollution in the project environment. Similarly, RSI of 4.03 for traffic congestion is also much higher than what obtains in the pre-construction phase. Besides, seven of the significant indices at this phase are not significant at the preconstruction phase, and these include water pollution, change in land use, impaired urban aesthetics, higher rental value, displacement of businesses, unstable income, and unemployment. This suggests that the road project has significant environmental and socio-economic impacts in the construction phase. 
Table 3: Construction phase environmental and socio-economic indices

\begin{tabular}{|c|c|c|c|c|c|c|c|c|c|}
\hline \multirow[t]{2}{*}{ Environmental indicators } & \multicolumn{5}{|c|}{$\begin{array}{c}\text { Impacts' significance ratings } \\
(\mathrm{n}=120)\end{array}$} & \multirow[t]{2}{*}{ SWV } & \multirow[t]{2}{*}{ RSI } & \multirow[t]{2}{*}{ MI } & \multirow[t]{2}{*}{ MD } \\
\hline & $\mathbf{1}$ & 2 & 3 & 4 & 5 & & & & \\
\hline Noise pollution & - & 4 & 11 & 43 & 62 & 523 & 4.36 & & 1.22 \\
\hline Water pollution & 4 & 22 & 53 & 31 & 10 & 381 & 3.18 & & 0.04 \\
\hline Air pollution & 7 & 9 & 58 & 45 & 1 & 384 & 3.20 & & 0.06 \\
\hline Flooding & 12 & 39 & 37 & 32 & - & 329 & 2.74 & & -0.40 \\
\hline Traffic congestion & 15 & 6 & 2 & 34 & 63 & 484 & 4.03 & & 0.89 \\
\hline Poor road condition & 10 & 8 & 1 & 74 & 27 & 460 & 3.83 & & 0.69 \\
\hline Poor road terminals & 9 & 3 & 56 & 34 & 18 & 409 & 3.41 & & 0.27 \\
\hline Encroachment on pedestrian facilities & 32 & 49 & 13 & 15 & 11 & 284 & 2.37 & 3.14 & -0.77 \\
\hline Frequent road accident & 11 & 35 & 31 & 39 & 4 & 350 & 2.92 & & -0.22 \\
\hline Vehicular/Pedestrian conflict & 10 & 15 & 35 & 34 & 26 & 411 & 3.43 & & 0.29 \\
\hline Frequent change in land use & 23 & 7 & 8 & 54 & 28 & 417 & 3.48 & & 0.34 \\
\hline Impaired urban aesthetics & 2 & 26 & 44 & 37 & 11 & 389 & 3.24 & & 0.10 \\
\hline Poor sanitation & 8 & 40 & 18 & 40 & 14 & 372 & 3.10 & & -0.04 \\
\hline Hindered access to adjoining neighbourhoods & 18 & 31 & 30 & 22 & 19 & 353 & 2.94 & & -0.20 \\
\hline Impaired mobility & 11 & 32 & 51 & 9 & 17 & 349 & 2.91 & & -0.23 \\
\hline \multicolumn{10}{|l|}{ Socio-economic indices } \\
\hline Crime/Insecurity & 16 & 26 & 31 & 44 & 3 & 352 & 2.93 & & -0.21 \\
\hline Housing shortage & 24 & 42 & 34 & 20 & - & 290 & 2.42 & & -0.72 \\
\hline Rental value & - & 33 & 10 & 67 & 10 & 414 & 3.45 & & 0.31 \\
\hline Displacement of businesses & 6 & 15 & 15 & 57 & 27 & 444 & 3.70 & & 0.56 \\
\hline Unstable Income source & 5 & 41 & 5 & 57 & 12 & 390 & 3.25 & & 0.11 \\
\hline Unemployment & 8 & 20 & 15 & 35 & 42 & 443 & 3.69 & 3.14 & 0.55 \\
\hline Access to shopping & 21 & 35 & 42 & 10 & 12 & 317 & 2.64 & & -0.50 \\
\hline Access to health & 12 & 36 & 43 & 10 & 19 & 348 & 2.90 & & -0.24 \\
\hline Children's access to education & 10 & 29 & 43 & 16 & 22 & 371 & 3.09 & & -0.05 \\
\hline Access to recreation facilities & 31 & 24 & 48 & 12 & 5 & 296 & 2.47 & & -0.67 \\
\hline Disruption of power supply & 25 & 32 & 39 & 23 & 1 & 303 & 2.53 & & -0.61 \\
\hline Disruption of water supply & 21 & 34 & 45 & 19 & 1 & 305 & 2.54 & & -0.60 \\
\hline Total & & & & & & & 84.75 & & \\
\hline
\end{tabular}

Source: Authors field survey, 2017

Specifically, socio-economic impacts in the form of business displacement, unemployment (job loss), increased rental value and unstable income were noticeable. It is normal to have environmental and socioeconomic impacts from road projects of this nature. Thus, the higher MI and RSI observed in this phase of the project are expected. However, the very high RSI of 4.36 and 4.03 for noise pollution and traffic congestion respectively suggest that adequate measures were not put in place to manage the very high adverse impacts. This is not strange as there was no clear evidence the assessment of the impact was done for the project.

\subsection{Post-Construction Phase Impacts}

The post-construction phase of the project is expected to produce more positive impacts in the study area. Analysis of the environmental and socio-economic indices for the post-construction phase as presented in Table 4 shows a mean index of 3.02 for the 27 variables which are relatively lower than the 3.14 obtained at the construction phase and very close to 3.00 obtained at the preconstruction phase.

Table 4 also reveals that 12 of the 27 variables have RSI higher than the mean index. The results show that the impacts observed at the post-construction phase are different from the construction phase. This is expected as the road project was initiated initially to mitigate some of the prevailing adverse environmental and socio-economic conditions before the project. However, some unanticipated adverse impacts were observed in the postconstruction phase. An example is an encroachment on pedestrian facilities (sidewalks) which has the highest RSI (4.20). Other significant impacts in this phase include increased rental value (3.90), better access to health facilities (3.77) and education facilities (3.72), noise pollution (3.68), mobility (3.67), access to shopping (3.67), access to adjoining neighbourhoods (3.66), unemployment (3.50), air pollution (3.44), access to recreation facilities (3.38) and displacement of business (3.07).

For a better comparison of the construction and postconstruction impacts with the baseline situation, the RSI of significant impact indicators in the three phases of the projects are presented in Table 5. The table reveals that 21 of the 27 impact indicators are significant across the three phases of the project. For instance, 13 of them were significant in the pre-construction phase, 15 in the construction phase and 12 in the post-construction phase. The results in the tables show that noise pollution was significant in the study area before the project; it became the most significant impact in the construction phase and had the least RSI in the post-construction phase. 
Table 4: Post-construction environmental and socio-economic indices

\begin{tabular}{|c|c|c|c|c|c|c|c|c|c|}
\hline \multirow[t]{2}{*}{ Environmental indicators } & \multicolumn{5}{|c|}{$\begin{array}{c}\text { Impacts' significance ratings } \\
(\mathrm{n}=120)\end{array}$} & \multirow[t]{2}{*}{ SWV } & \multirow[t]{2}{*}{ RSI } & \multirow[t]{2}{*}{ MI } & \multirow[t]{2}{*}{ MD } \\
\hline & 1 & 2 & 3 & 4 & 5 & & & & \\
\hline Noise pollution & - & 38 & 57 & 64 & 18 & 441 & 3.68 & & 0.66 \\
\hline Water pollution & 17 & 37 & 37 & 24 & 5 & 323 & 2.69 & & -0.33 \\
\hline Air pollution & 5 & 16 & 28 & 63 & 8 & 413 & 3.44 & & 0.42 \\
\hline Flooding & 23 & 51 & 40 & 6 & - & 269 & 2.24 & & -0.78 \\
\hline Traffic congestion & 26 & 32 & 18 & 36 & 8 & 328 & 2.73 & & -0.29 \\
\hline Poor road condition & 32 & 36 & 48 & 3 & 1 & 265 & 2.21 & & -0.81 \\
\hline Poor road terminals & 36 & 71 & 7 & 2 & 4 & 227 & 1.89 & & -1.13 \\
\hline Encroachment on pedestrian facilities & 1 & 6 & 10 & 54 & 49 & 504 & 4.20 & 3.02 & 1.18 \\
\hline Frequent road accident & 28 & 64 & 25 & 2 & 1 & 244 & 2.03 & & -0.99 \\
\hline Vehicular/Pedestrian conflict & 24 & 12 & 75 & 7 & 2 & 311 & 2.59 & & -0.43 \\
\hline Frequent change in land use & 5 & 42 & 36 & 24 & 13 & 358 & 2.98 & & -0.04 \\
\hline Impaired urban aesthetics & 18 & 26 & 42 & 16 & 18 & 350 & 2.92 & & -0.10 \\
\hline Poor sanitation & 23 & 65 & 15 & 10 & 7 & 273 & 2.28 & & -0.74 \\
\hline Hindered access to adjoining neighbourhoods & - & 14 & 49 & 21 & 36 & 439 & 3.66 & & 0.64 \\
\hline Impaired mobility & 9 & 4 & 26 & 60 & 21 & 440 & 3.67 & & 0.65 \\
\hline \multicolumn{10}{|l|}{ Socio-economic indices } \\
\hline Crime/Insecurity & 24 & 47 & 28 & 15 & 6 & 292 & 2.43 & & -0.59 \\
\hline Housing shortage & 10 & 50 & 47 & - & 13 & 316 & 2.63 & & -0.39 \\
\hline Rental value & - & 16 & 29 & 26 & 49 & 468 & 3.90 & & 0.88 \\
\hline Displacement of businesses & 3 & 33 & 52 & 17 & 15 & 368 & 3.07 & & 0.05 \\
\hline Unstable Income source & 14 & 25 & 58 & 20 & 3 & 333 & 2.78 & & -0.24 \\
\hline Unemployment & 2 & 27 & 37 & 17 & 37 & 420 & 3.50 & 3.02 & 0.48 \\
\hline Access to shopping & 5 & 12 & 33 & 38 & 32 & 440 & 3.67 & & 0.65 \\
\hline Access to health & 3 & 6 & 40 & 38 & 33 & 452 & 3.77 & & 0.75 \\
\hline Children's access to education & 1 & 5 & 51 & 33 & 30 & 446 & 3.72 & & 0.70 \\
\hline Access to recreation facilities & 9 & 8 & 59 & 17 & 27 & 405 & 3.38 & & 0.36 \\
\hline Disruption of power supply & 13 & 33 & 59 & 15 & - & 316 & 2.63 & & -0.39 \\
\hline Disruption of water supply & 11 & 32 & 49 & 27 & 1 & 335 & 2.79 & & -0.23 \\
\hline Total & & & & & & & 81.48 & & \\
\hline
\end{tabular}

Source: Authors field survey, 2017

Table 5: RSI of impact indicators in the three project phases

\begin{tabular}{lccc}
\hline \multirow{2}{*}{ Impact indicators } & \multicolumn{3}{c}{ Project phases } \\
\cline { 2 - 4 } Noise pollution & Pre-construction (RSI) & Construction (RSI) & Post-construction (RSI) \\
Water pollution & 3.76 & $\mathbf{4 . 3 6}$ & $\mathbf{3 . 6 8}$ \\
Air pollution & 2.27 & $\mathbf{3 . 1 8}$ & 2.69 \\
Traffic congestion & 3.49 & $\mathbf{3 . 2 0}$ & $\mathbf{3 . 4 4}$ \\
Poor road condition & 3.77 & $\mathbf{4 . 0 3}$ & 2.21 \\
Poor road terminals & 3.45 & $\mathbf{3 . 8 3}$ & 1.89 \\
Encroachment on pedestrian facilities & 3.55 & $\mathbf{3 . 4 1}$ & $\mathbf{4 . 2 0}$ \\
Vehicular/Pedestrian conflict & 2.77 & 2.37 & 2.59 \\
Frequent change in land use & 3.03 & $\mathbf{3 . 4 3}$ & 2.98 \\
Impaired urban aesthetics & 2.53 & $\mathbf{3 . 4 8}$ & 2.92 \\
Poor sanitation & 2.54 & $\mathbf{3 . 2 4}$ & 2.28 \\
Hindered access to adjoining neighbourhoods & 3.01 & 3.10 & $\mathbf{3 . 6 6}$ \\
Impaired mobility & 3.51 & 2.94 & $\mathbf{3 . 6 7}$ \\
Rental value & 3.18 & 2.91 & $\mathbf{3 . 9 0}$ \\
Displacement of businesses & 2.85 & $\mathbf{3 . 4 5}$ & $\mathbf{3 . 0 7}$ \\
Unstable income source & 2.60 & $\mathbf{3 . 2 5}$ & 2.78 \\
Unemployment & 2.33 & $\mathbf{3 . 6 9}$ & $\mathbf{3 . 5 0}$ \\
Access to shopping & 2.98 & 2.64 & $\mathbf{3 . 6 7}$ \\
Access to health & 3.63 & 2.90 & $\mathbf{3 . 7 7}$ \\
Children's access to education & 3.65 & 3.09 & $\mathbf{3 . 7 2}$ \\
Access to recreation facilities & 3.84 & 3.47 & 3.38
\end{tabular}

Source: Authors Analysis 


\subsection{Assessment of Mitigating Measures}

This section appraises the various mitigating measures adopted to manage the adverse impacts of the road upgrade. Of the 27 listed impacts, 20 of them were considered significant in both construction and postconstruction phases. However, respondents' assessment of the mitigating measures presented in Table 6 indicates that only 15 of these impacts had visible mitigating measures. Results presented in the table indicate that 11 of the 15 mitigating measures were effective. The percentage of respondents who regarded these measures as an effective range from $61 \%$ to $99 \%$. Consequently, the mitigating measures deployed to manage hindered access to adjoining neighbourhoods was regarded as the most effective (99\%). The measures deployed against this impact include diversion of traffic and use of mass media to inform the residents of the host community about the traffic management measures.

Table 6: Respondents' assessment of the mitigating measures

Project impact

Mitigating measure
Effectiveness (\% of respondents) Effective Ineffective

Impaired access Poor road condition

Poor road terminals

Traffic congestion

Misuse of pedestrian facilities

Impaired urban aesthetics

Road accident

Vehicular/pedestrian conflict

Crime/insecurity

Poor sanitation

Noise pollution

Air pollution

Flooding

Displacement of business

Change in land use

\section{Diversion of traffic and mass media announcement to that} effect

Quality road construction and use of quality materials the proper definition of terminals, delineation of boundaries, lighting, layout and toilet provision

Traffic diversion and use of traffic officials

Barricading and preventing commuters from crossing the highway

Urban design application to the construction of the pedestrian bridge, terminals and roads

Placement of safety/traffic signs; deployment of traffic and road safety personnel

Construction of sidewalks/erection of barricade to prevent commuters from crossing highway

Deployment of the police and other security agencies

Constant site cleaning

Avoidance of use of noise-making equipment/ elimination of unnecessary public audios.

\begin{tabular}{cc}
99.0 & 1.0 \\
98.0 & 2.0 \\
92.0 & 8.0 \\
90.0 & 10.0 \\
86.0 & 14.0 \\
80.0 & 20.0 \\
77.0 & 23.0 \\
75.0 & 25.0 \\
68.0 & 32.0 \\
63.0 & 37.0 \\
61.0 & 39.0 \\
45.0 & 55.0 \\
43.0 & 57.0 \\
37.0 & 63.0 \\
37.0 & 63.0 \\
\hline
\end{tabular}

Construction of proper drainage channels

Compensation

Compensation/consultation with stakeholders

Source: Authors field survey, 2017

Other adverse impacts whose mitigating measures were considered adequate include poor road condition, poor road terminals, traffic congestion, misuse of pedestrian facilities, impaired urban aesthetics, road accident, vehicular/pedestrian conflict, crime/insecurity, poor sanitation and noise pollution. Interestingly, noise pollution rated as the worst impact in the construction phase is the least $(61 \%)$ among the impacts with effective mitigating measures. The primary measure deployed to mitigate this impact was the avoidance of the use of noisemaking equipment. The other four impacts whose mitigating measures were considered ineffective include air pollution, flooding, displacement of businesses and change in land use. Displacement of businesses and change in land use were considered as impacts with the most ineffective mitigating measures. This suggests that compensation of and engagement with owners of affected businesses were not well-managed. Impacts of the project without any visible mitigating measure in both construction and post-construction phase include unemployment, higher rental value, unstable income, water pollution and encroachment on sidewalks. The lack of measures to mitigate these impacts exclude them from those listed in Table 6.

\section{Discussion of Findings}

The assessment of the environmental and social impacts of road upgrade in the project area, as documented in this study produces some outcomes that are not usually found in the literature. For instance, the magnitude of the road project reviewed in this study requires that a proper impact assessment is done before the project execution phase. However, there was no evidence that relevant government agencies did such a study. Consequently, the findings in this study may be a true reflection of the absence of an impact assessment study on the project.

This study established that the prevailing environmental and socio-economic conditions of the project area before the road improvement were poor. This is attributed to weak planning control and poor integration of land use and transport planning, thus necessitating the road improvement project which includes the construction of a 3-legged pedestrian bridge and walkways for vehicular/pedestrian segregation, roadway improvement in the form of the slip road, rotary junction, road widening, creation of three parking areas, relocation of market, road signs, speed control, traffic signal, safety and 
security measures and control of environmental nuisances in the project area. Soneye (2010), in his study of the environmental impacts of the upgrade of another major highway in Lagos metropolis also supported the claim that these areas are usually subjected to various transportation challenges that often lead to public outcry. The roads upgrading and provision projects are the responses of government to the outcries of the residents of these areas. The perceived environmental and socio-economic situations during and after the project compared with the baseline situation showed that the project produced some adverse impacts, the most prominent being noise pollution at the construction phase. This is not at variance with what obtains in literature, and there are practical ways of dealing with such impact. For instance, Towers (2001) argued that identifying the noise problems at the design phases of the project is the most important thing to do so that appropriate mitigating measures can be specified proactively, before the start of the construction. Similarly, Wanjiku (2014) also posited that adverse impacts associated with the construction of highways are predominantly environmental impacts such as pollution and the loss of biodiversity within the environment.

The social and economic impacts of road projects are also positive and beneficial to the host communities. This study presents that some of the benefits of the project on the host community are, the enhance physical environment, improved security, increased accessibility and mobility, increase in land value, improved standard of living of residents and the provision of employment opportunities. These are some of the beneficial environmental, social and economic impacts of road projects. Bogale (2016) in his study of the impacts of three major highways in Ethiopia also discovered that there are more positive and less negative temporal and spatial socio-economic impacts generated by the three corridors notwithstanding their locational disparities.

In the absence of evidence of an existing impact assessment report, this study established that the road improvement project has helped to deal with the hitherto poor transport and land use challenges in the project area. The study also established that the mitigating measures deployed to manage the adverse impacts of the project were generally effective, but ineffective for impacts such as air pollution, flooding, displacement of businesses and change in land use. Where impacts of road development are not properly predicted and analysed, some of the

\section{References}

Alamgir M., Campbell M.J., Sloan S., Goosem M., Clements G.R., Mahmoud I.M., and Laurance W.F. (2017). Economic, Socio-Political and Environmental Risks of Road Development in the Tropics. Current Biology, vol. 27, R1130-R1140.

Alamgir M., Campbell M.J., Sloan S., Phin W.E., and Laurance W.F. (2018). Impact Assessments in Malaysian Road Infrastructure Projects. Jurtera, the Institution of Engineers, Malaysia, 13-16.

Arethun T, and Bhatta B. (2012). Contribution of Rural Roads to Access to- and Participation in Markets: Theory and Results from Northern Ethiopia. Journal of Transportation Technology, vol. 2, No 1, 165-174. mitigating measures adopted in addressing the environmental and social impacts of roads and other developments are little more than window-dressing (Alamgir et al., 2017).

\section{Conclusion}

The provision and expansion of roads have been on the rise in most Nigerian cities in recent times. These road projects have transformative effects on the environment, economies and societies which should be discussed and considered publicly. This study has examined the OjoduBerger road expansion projects in Lagos and identified the various social and environmental impacts associated with this project. The relevance of this study lies in its potential to provide valuable information that can serve as a guide to adopting best practices in the delivery of road projects in urban areas. The study concludes that where no impact study is done for road development or improvement in urban areas, the use of local perception remains an excellent approach to appraising project impacts. Based on the findings in this study, it is recommended that in the future, government agencies responsible for urban road development should follow best practices in project impact assessment before construction. This should involve adequate community consultation and engagement of people in the host community as a way of achieving sustainable project development in the road transport sector. This aligns with the position of Chen (2001) who submitted that the effects of subway construction on host communities in China were expertly managed by predicting and analyzing the social risks and potential social conflicts in advance. It is clear from this study that some adverse impacts of the road upgrade could not be adequately mitigated as some of them were beyond the scope of government intervention. Such impacts include unemployment/job loss, higher rental value and income instability. In the future, such impacts should be anticipated, predicted and managed adequately for social and political equity.

\section{Acknowledgement}

My research assistants: Tosin Aloba and Ojo Benjamin are well appreciated for their assistance in the fieldwork, literature sourcing and editorial work.

Asner, G.P., Llactayo, W., Tupayachi, R., and Luna, E.R. (2013). Elevated rates of gold mining in the Amazon revealed through high-resolution monitoring. Proc. Natl. Acad. Sci. USA, vol. 110, 18454-18459.

Bambach, M.R., and Mitchell, R.J. (2015). Estimating the human recovery costs of seriously injured road crash casualties. Accident Analysis Preview, vol. 85, 177-185.

Bogale, B. D. (2016). Socioeconomic Impacts Of Road Development In Ethiopia: Case Studies Of Gendewuha - Gelago, Mile - Weldiya And Ginchi Kachisi Roads. South Africa: Department Of Geography, University of South Africa.

Brealey, R., Myers, S., and Allen, F. (2011). Principles of Corporate Finance, 10th Edition. New York: McGrawHill. 
Bryceson, D.F., Bradbury, A., and Bradbury, T. (2008). Roads to poverty reduction? Exploring rural roads' impact on mobility in Africa and Asia. Development Policy Review, vol. 26, 459-482.

Carswell, J. (1987). HIV infection in healthy persons in Uganda. AIDS 1, 223-227.

Clements, G.R., Lynam, A.J., Gaveau, D., Yap, W.L., Lhota, S., Goosem, M., Laurance, S., and Laurance, W.F. (2014). Where and how are roads endangering mammals in Southeast Asia's Forests. PLoS ONE 9, e1 15376.

Clevenger, A.P., Chruszcz, B., and Gunson, K.E. (2003). Spatial patterns and factors influencing small vertebrate fauna road-kill aggregations. Biology Conservation, vol. 109, 15-26.

Collier, P., Kirchberger, M., and Sonderbom, M. (2015). The cost of road infrastructure in low and middle income countries. Washington, DC: World Bank.

Colombijn, F. (2002). Introduction: on the road. Journal of Humanities Social Science Southeast Asia, vol. 158, 595-617.

Dulac, J. (2013). Global land transport infrastructure requirements: Estimating road and railway infrastructure capacity and costs to 2050. Paris, France: International Energy Agency.

Ethiopian Roads Authority (2012). Universal Rural Road Access Program. Addis Ababa.

Hecht, S.B., and Cockburn, A. (2010). The Fate of the Forest: Developers, Destroyers and Defenders of the Amazon, Updated Edition. Chicago, USA: The University of Chicago Press.

Ijigah E.A., Jimoh R.A., Aruleba B.O., \& Ade A.B. (2013). An Assessment of Environmental Impacts of Building Construction Projects. Civil and Environmental Research 3(1), 93-105.

Kociolek, A.V., Clevenger, A.P., St. Clair, C.C., and Proppe, D.S. (2011). Effects of road networks on bird populations. Conservation Biology, vol. 25, 241-249.

Koji, T., and Hoban, C. (1997). Roads and the Environment: a Handbook. Washington, DC: The World Bank.

LAMATA. (2012). Environmental and Social Impact Assessment for the Construction of the Mile 12 (Kosofe Local Government Area) to Ikorodu Town (Ikorodu West Local Government Area) Bus Rapid Transit (BRT). Lagos: Lagos Metropolitan Area Transport Authority.

Laurance, W.F., Clements, G.R., Sloan, S., O'Connell, C.S., Mueller, N.D., Goosem, M., Venter, O., Edwards, D.P., Phalan, B., Balmford, A., et al. (2014). A global strategy for road building. Nature, vol. 513, 229232 .

Laurance, W.F., Goosem, M., and Laurance, S.G.W. (2009). Impacts of roads and linear clearings on tropical forests. Trends Ecology Evolution, vol. 24, 659-669.

Laurance, W.F., Peletier-Jellema, A., Geenen, B., Koster, H., Verweij, P., Van Dijck, P., Lovejoy, T.E., Schleicher, J., and van Kuijk, M. (2015). Reducing the global environmental impacts of rapid infrastructure expansion. Current Biology, vol 25, R259-R262.

McSweeney, K., Nielsen, E.A., Taylor, M.J., Wrathall, D.J., Pearson, Z., Wang, O., and Plumb, S.T. (2014). Drug policy as conservation policy: Narcodeforestation. Science, vol. 343, 489-490.
Morgan, R. (2012). Environmental Impact Assessment: the state of the art. Impact Assess Project Appraisal 30(1), 5-14.

Ojo, O. (1988). Urbanization and Thermal Problems in Tropical Cities: The Lagos Experience. Environmental Issues and Management in Nigerian Development (pp. 291-305). Ile-Ife, Nigeria: Obafemi Awolowo University.

Perkins, D. (2011). Project on Environmentally Sustainable Transport (EST). Paris: Policy Guidelines for EST. EAI.

Rudel, T. (2005). Tropical Forests: Regional Paths of Destruction and Regeneration in the Late 20th Century. New York: Columbia University Press.

Singleton, I., Wich, S., Husson, S., Stephens, S., Atmoko, S.U., Leighton, M., Rosen, N., Traylor-Holzer, K., Lacy, R., and Byers, O. (2004). Orangutan population and habitat viability assessment: final report. Apple Valley, MN, USA: IUCN/SSC Conservation Breeding Specialist Group.

Sodhi, N.S., Koh, L.P., Brook, B.W., and Ng, P.K.L. (2004). Southeast Asian biodiversity: an impending disaster. Trends Ecology Evolution, vol. 19, 654-660.

Soneye, A. (2004). Institutional Dilemma of Urban Waste Management in Developing Nations: the Lagos State Experience. In M. Adejuyigbe, Industrialization, Urbanization and Development in Nigeria: $1950-1999$ (pp. 169-175). Lagos: Concept Publication.

Soneye, A. (2007). Environmental and Human Impacts of Dredging River Niger: A Comparative GIS Analysis. The Nigerian Journal of Business and Social Sciences, vol. 1, No 1, 111 - 123.

Soneye, A. (2010). Environmental Impacts of Road Transport Development in Nigeria: An Assessment of Lagos - Ikorodu Highway Using GIS. Interdisciplinary Journal of Contemporary Research in Business (IJCRB), October, vol. 2, 24 - 37.

Sua'rez, E., Morales, M., Cueva, R., Bucheli, V.U., Zapata-Rı'os, G., Toral, E., Torres, J., Prado, W., and Olalla, J.V. (2009). Oil industry, wild meat trade and roads: indirect effects of oil extraction activities in a protected area in north-eastern Ecuador. Animal Conservation, vol. 12, 364-373.

Trombulak, S.C., and Frissell, C.A. (2000). Review of ecological effects of roads on terrestrial and aquatic communities. Conservation Biology, vol. 14, 18-30.

Walsh, P.D., Henschel, P., Abernethy, K.A., Tutin, C.E.G., Telfer, P., and Lahm, S.A. (2004). Logging speeds Little Red Fire Ant invasion of Africa. Biotropica, vol. 36, 637-641.

Wanjiku, E. M. (2014). Socio-Economic Benefits and Environmental Impacts of Thikaroad Superhighway. Kenya: Environmental Planning and Management, Kenyatta University.

Watson, J.E.M., Shanahan, D.F., Di Marco, M., Allan, J., Laurance, W.F., Sanderson, E.W., Mackey, B., and Venter, O. (2016). Catastrophic declines in wilderness areas undermine global environment targets. Current Biology, vol. 26, 2929-2934.

Whitworth, A., Beirne, C., Rowe, J., Ross, F., Acton, C., Burdekin, O., and Brown, P. (2015). The response of faunal biodiversity to an unmarked road in the Western Amazon. Biodiversity Conservation, 1657-1670. 
Wijnen, W., and Stipdonk, H. (2016). Social costs of road crashes: an international analysis. Accident Analysis Preview, vol. 94, 97-106.

Xue, X., Zhang, R., Zhang, X., Jing, R., Li, Y \& Li, H. 2015. Environmental and social challenges for urban subway construction: An empirical study in China. International Journal of Project Management, 33 (2015) 576-588, Available online at www.sciencedirect.com 